\title{
Carbon Monoxide Poisoning Due to Water Pipe Smoking: Case Series
}

\author{
Abdullah Osman Koçak, Ilker Akbaş, Zeynep Çakır \\ Department of Emergency Medicine, Atatürk University School of Medicine, Erzurum, Turkey
}

\begin{abstract}
Introduction: Water pipe is a different form of tobacco consumption. In recent years, water pipe usage has become increasingly widespread. The thought that it is less harmful than cigarettes increases its usage. Long-term exposure to high carbon monoxide levels due to water pipe consumption may cause carbon monoxide poisoning.

Case Report: We present four patients aged 18-29 who consulted our emergency department with complaints regarding fainting, blackout, and headache. While three of them consumed water pipe, one who was a non-consumer, was in an environment in which water pipe was consumed. Carboxyhemoglobin values of the patients were between 18.7\%-35.5\%. Our patients received one session of hyperbaric oxygen treatment. Patients with improved clinical situations after treatment were discharged.

Conclusion: Water pipe consumption is the most observed form of tobacco consumption in the Eastern-Mediterranean Region, followed by in the US. Although it is considered that all toxic agents are filtered while water pipe smoke passes through water, water pipe consumption increases levels of carcinogens, carbon monoxide, nicotine, and tar in the blood compared to smoking. It is striking that carboxyhemoglobin values of our cases are as high as, or even higher than, that in stove poisoning cases. It must be kept in mind that non-specific symptoms following water pipe consumption may be symptoms of carbon monoxide poisoning.
\end{abstract}

Keywords: Water pipe smoking, carbon monoxide poisoning, hyperbaric oxygen therapy

Received: 31.03.2016 Accepted: 17.05.2016 Available Online Date: 24.10.2016

\section{Introduction}

Smoking a water pipe, also known as shisha, hookah, or hubble-bubble in different regions of the world, is a different way of consuming tobacco $(1,2)$. Water pipes have been widely used in Southeastern Asia and Africa for 400 years, and in recent years, they have become popular in Europe and America, especially among youngsters $(3,4)$. The belief that it is less harmful than cigarettes because of its pleasant taste and aroma is one of the most important reasons for the increase in its usage (1). Compared to cigarettes, it contains carbon monoxide (CO), heavy metals, and nicotine in higher concentrations (4). Long-term exposure to the high $\mathrm{CO}$ levels found in its contents may cause CO poisoning (1). In this study, our objective was to discuss four CO poisoning cases with different clinical manifestations after water pipe smoking and to draw attention to the risks of water pipe use, which emerge in the early stages of use and are not widely known.

\section{Case Reports}

Case 1. An 18-year-old male patient, who complained of syncope, was brought to the emergency department by ambulance and admitted. The patient, who had a normal medical history, had not experienced syncope previously. He was not a smoker. For three hours, he sat with his friends in a cafe, where people smoked a water pipe, but he did not. He stated that he had a headache and felt dizzy after he left the cafe, and he could not remember what happened afterwards. People who witnessed the incident stated that he had fainted for approximately 4 to 5 minutes, but he had not displayed spasms or symptoms of an epileptic seizure. His vital measurements were normal at admission, and his Glasgow Coma Scale (GCS) score was 15. He was

This study was presented at the e-poster in $10^{\text {th }}$ European Congress on Emergency Medicine, 1-5 October 2016, Vienna, Austria.

\section{Address for Correspondence:}

Ilker Akbaş, Department of Emergency Medicine, Atatürk University School of Medicine, Erzurum, Turkey

E-mail: akbasilker@gmail.com

oCopyright 2017 by Emergency Physicians Association of Turkey - Available online at www.jemcr.org 
Table 1. General characteristics of our cases

\begin{tabular}{|c|c|c|c|c|c|c|c|}
\hline & Age & Gender & Symptoms & $\begin{array}{l}\text { Exposure } \\
\text { duration }\end{array}$ & $\begin{array}{c}\text { Habit of } \\
\text { cigarette smoking }\end{array}$ & $\begin{array}{l}\text { COHb level } \\
\text { at admission }\end{array}$ & Treatment \\
\hline Case 1 & 18 & Male & $\begin{array}{l}\text { Headache } \\
\text { Dizziness } \\
\text { Syncope }\end{array}$ & $\begin{array}{l}3 \text { hours (he did not } \\
\text { smoke personally, } \\
\text { environmental exposure) }\end{array}$ & No & 18.7 & $\begin{array}{c}\text { HBOT and } \\
\text { high dose oxygen } \\
\text { with the respiratory mask }\end{array}$ \\
\hline Case 2 & 21 & Male & $\begin{array}{l}\text { Headache } \\
\text { Dizziness } \\
\text { Nausea } \\
\text { Syncope }\end{array}$ & $\begin{array}{c}2 \text { hours (he smoked } \\
1 \text { water pipe) }\end{array}$ & Yes & 29.2 & $\begin{array}{c}\text { HBOT and } \\
\text { high dose oxygen } \\
\text { with the respiratory mask }\end{array}$ \\
\hline Case 3 & 29 & Male & $\begin{array}{l}\text { Dizziness } \\
\text { Nausea } \\
\text { Vomiting } \\
\text { Palpitation }\end{array}$ & $\begin{array}{c}3 \text { hours (he smoked } \\
1 \text { water pipe) }\end{array}$ & Yes & 34.1 & $\begin{array}{c}\text { HBOT and } \\
\text { high dose oxygen } \\
\text { with the respiratory mask }\end{array}$ \\
\hline
\end{tabular}

conscious, oriented, and cooperative. Physical examination was normal, and there was no focal neurological deficit. Electrocardiography (ECG) displayed normal sinus rhythm. There was no sign of gastrointestinal system (GIS) bleeding during the digital rectal examination, and computed tomography (CT) of the brain was normal. The carboxyhemoglobin $(\mathrm{COH} b)$ value in the arterial blood gas ( $\mathrm{ABG}$ ) was $18.7 \%$ (normal range is $0.5-1.5 \%$ ), and other laboratory parameters were within the normal limits.

One hyperbaric oxygen therapy (HBOT) session was carried out with the patient, with syncope in his anamnesis and then high-dose oxygen (10 L/min) was administered with a respiratory mask for 24 hours. He was discharged after the $\mathrm{COHb}$ value dropped to $1.1 \%$.

Case 2. A 20-year-old male patient was admitted to the emergency department by ambulance with syncope and head trauma. The patient, who had not experienced syncope before, had a normal medical history. He had been in a cafe for two hours where he and other people smoked water pipes. After leaving the cafe, he had a headache, felt dizzy, and fainted after vomiting, hitting the right side of his head on the ground. According to statements from witnesses, the syncope lasted approximately 3 minutes and there was no evidence of an epileptic seizure. He had been a smoker for 5 years (1-1.5 packs a day), and he smoked a water pipe at least two times a month. However, he stated that this time he finished the tobacco much faster than he was used to. His vital signs were normal. GCS score was 15. He was conscious, oriented, and cooperative. Physical examination revealed only a small dermabrasion on the right frontal region of his head. Examination of his other functions was normal. There was no focal neurological deficit, and ECG showed normal sinus rhythm. There was no finding of GIS bleeding in the digital rectal examination. CT of the brain, which was carried out due to the trauma and syncope, was considered normal. The measured $\mathrm{COHb}$ value in the patient's ABG was $29.2 \%$. One HBOT session was administered to the patient, who had syncope in his medical history and a $\mathrm{COHb}$ value higher than 25\% (normal range: 0.5 to 1.5\%).
Afterwards, high-dose oxygen (10 L/min) was administered with a respiratory mask for 24 hours. The patient was discharged after the $\mathrm{COHb}$ value dropped to $2 \%$.

Case 3. A 29-year-old male patient was admitted by his friends to the emergency department. For three hours, the patient was with people who were smoking water pipes, and he had also consumed one water pipe on the same day of admission. He had experienced nausea, vomiting, dizziness, and palpitations, which started half an hour before he came to the emergency department. He had no known systemic disease in his medical history, but he smoked a pack of cigarettes a day for about 10 years. He occasionally smokes a water pipe, but he had never experienced such an event before. He had tachycardia (109 beats/min), and other vital signs were within normal levels. There were no significant findings on physical examination. ECG revealed sinusoidal tachycardia (105 beats/min) and the $\mathrm{COHb}$ value in $\mathrm{ABG}$ was measured at $34.1 \%$ (normal range: 0.5-1.5\%). Therefore, following one HBOT session, high-dose oxygen (10 L/min) was administered to the patient with a respiratory mask for 24 hours. During the follow-up, the $\mathrm{COHb}$ value dropped to $3 \%$ and the patient was discharged the next day.

Case 4. A 28-year-old male patient was brought by his relatives to the emergency department due to a clouding of consciousness with no recognition of his environment or people. The patient had consumed two consecutive water pipes within six hours, and his complaints started a half an hour before he was admitted to the emergency department. There was no known disorder in his medical history. He has had a smoking habit for about 15 years (1.5 packs a day). His vital signs were normal, except for the tachycardia (105 beats/min). GCS score was 12 (E:3, V:4; M:5). He was confused and not oriented to person and place. Neurological examination did not reveal any focal neurological deficit, and other functions were normal. The $\mathrm{COHb}$ value was measured in $\mathrm{ABG}$ at $35.5 \%$ (normal range: $0.5-1.5 \%)$. There was no pathological finding on brain CT. Due to the high $\mathrm{COHb}$ level and clouding of consciousness, following one 
Table 2. Blood levels caused by environmental $\mathrm{COHb}$

\begin{tabular}{|ccc|}
\hline CO amount in the air & & $\mathrm{COHb}$ in blood (\%) \\
\hline$\%$ & $\mathrm{ppm}$ & 2 \\
\hline 0.001 & 10 & 10 \\
\hline 0.007 & 70 & 20 \\
\hline 0.012 & 120 & 30 \\
\hline 0.022 & 220 & $40-/ 50$ \\
\hline $0.035-0.052$ & $350-/ 520$ & $60-/ 80$ \\
\hline $0.080-0.195$ & 1950 & \\
\hline CO: carbon monoxide; COHb: carboxyhemoglobin
\end{tabular}

HBOT session, the patient was treated with high-dose oxygen (10 L/ min) administered with a respiratory mask for 24 hours. $\mathrm{COHb}$ level dropped to $3.1 \%$ and cognition became normal. He was discharged on the following day.

The general characteristics of our cases are summarized in Table 1.

\section{Discussion}

Regarding the latest epidemiological data, the water pipe is the most common form of tobacco consumption in the Eastern Mediterranean region and the second most common in the United States of America (2). Water pipes consist of a ceramic bowl, a glass bottle, and a hose, which is used for inhaling the smoke. An aromatized and sugared mixture of tobacco is placed in the ceramic bowl. The tobacco is then lit with charcoal, with the tobacco and charcoal separated from each other with a piece of aluminum foil. The ceramic bowl is connected with a pipe stem to the bottle, and the bottle is half-filled with water. Connected to the upper part of the bottle is the pipe, where the smoker draws on the mixture of tobacco and charcoal smoke (5). Although, it is believed that all toxic substances are filtrated during the passage through the water; in fact, only a small part of the toxins are filtrated (1). Tobacco consumption with a water pipe causes higher blood concentration of carcinogenic substances, CO, nicotine, and tar than that with cigarette smoking (3).

$\mathrm{CO}$ poisoning is diagnosed by measurement of blood $\mathrm{COHb}$ levels (6). $\mathrm{COHb}$ is produced endogenously with the catabolism of the hemoglobin in the body, but the level of endogenic $\mathrm{COHb}$ does not exceed 1-2\%. In cigarette smokers, the levels are around 5-6\% (3, 6). Patient symptoms of $\mathrm{CO}$ poisoning are not diagnostic at the first admission to emergency departments (4). The broad spectrum of clinical findings and the non-specific character of the clinical symptoms delay the diagnosis and, consequently, the treatment, which increases the risk of complications $(7,8)$. Since our patients presented to the emergency departments with non-specific symptoms of nausea, vomiting, headache, weakness, dizziness, presyncope, and syncope, we recommend that CO poisoning should be kept in mind during the differential diagnosis by the emergency physicians.

Heaters, exhaust gases from vehicles, generators, and coal burning stoves are the most common sources of $\mathrm{CO}$ poisoning (4). In a study conducted in Turkey, $85 \%$ of the CO poisoning cases were caused by coal-burning stoves, and the mean $\mathrm{COHb}$ value was $21.6 \%$ (9). It is remarkable that the $\mathrm{COHb}$ values in our cases of $\mathrm{CO}$ poisoning after water pipe smoking was as high as, and even higher than, coal stove poisoning.

The CO concentration in the air is below $1 \mathrm{ppm}$. As its specific gravity is greater than air, it sinks towards the ground. In Table 2, the blood $\mathrm{COHb}$ values are summarized according to the environmental $\mathrm{CO}$ levels $(3,10)$. We noticed that our first case experienced CO poisoning, even though he did not personally smoke a water pipe.

It was estimated that damage to the human body by a single event of water pipe smoking was equal to smoking 100 to 200 cigarettes (4). Because water pipes last longer than a cigarette and higher volumes are inhaled, exposure to $\mathrm{CO}$ during water pipe smoking is higher than that during cigarette smoking, and charcoal, which is used to light the tobacco, delivers extra CO particles. Moreover, because the water pipe is usually smoked in closed spaces, the particles spreading through the air is also a source of exposure. Exposure to CO during an hour-long water pipe smoke is seven times higher than cigarette smoking (1). And although water pipe usage among adolescents is as high as 15\% in the United States of America, there are only limited case reports on $\mathrm{CO}$ poisoning in the literature $(3,4$, $6,7)$.

\section{Conclusion}

The clinical manifestation of CO poisoning is non-specific and can be confused with several other diseases. The clinical findings can extend from flu-like symptoms to coma. It should be kept in mind that the non-specific symptoms manifesting after smoking a water pipe might be due to poisoning.

The case report has written in an anonymous characteristic, thus secret and detailed data about the patient has removed. Editor and reviewers can know and see these detailed data. These data are backed up by editor and by reviewers.

Informed Consent: Written informed consent not was obtained from the patients.

Peer-review: Externally peer-reviewed.

Author contributions: Concept - Z.Ç., A.O.K., I.A.; Design - Z.Ç., A.O.K., I.A.; Supervision - Z.C.., A.O.K., I.A.; Resource - Z.Ç., I.A.; Materials - Z.Ç., A.O.K., Data Collection and/or Processing - Z.C.., I.A.; Analysis and/or Interpretation - Z.Ç., A.O.K., I.A.; Literature Search - Z.C.., A.O.K., I.A.; Writing - Z.Ç., A.O.K., I.A.; Critical Reviews - Z.Ç., A.O.K., I.A.

Conflict of Interest: No conflict of interest was declared by the authors.

Financial Disclosure: The authors declared that this study has received no financial support.

\section{References}

1. Karaca Y, Eryigit U, Aksut N, Turkmen S. Syncope associated with water pipe smoking. BMJ Case Rep 2013; 2013.

2. Maziak W, Jawad M, Jawad S, Ward KD, Eissenberg T, Asfar T. Interventions for waterpipe smoking cessation. Cochrane Database Syst Rev 2015; CD005549. [CrossRef] 
3. Ashurst JV, Urquhart M, Cook MD. Carbon monoxide poisoning secondary to hookah smoking. J Am Osteopath Assoc 2012; 112: 686-8.

4. Ozkan S, Ozturk T, Ozmen Y, Durukan P. Syncope Associated with Carbon Monoxide Poisoning due to Narghile Smoking. Case Rep Emerg Med 2013; 2013: 796857. [CrossRef]

5. Aboaziza E, Eissenberg T. Waterpipe tobacco smoking: what is the evidence that it supports nicotine/tobacco dependence? Tobacco control 2015; 24 Suppl 1: i44-i53. [CrossRef]

6. Turkmen S, Eryigit U, Sahin A, Yeniocak S, Turedi S. Carbon monoxide poisoning associated with water pipe smoking. Clin Toxicol (Phila) 2011; 49: 697-8. [CrossRef]
7. von Rappard J, Schonenberger M, Barlocher L. Carbon monoxide poisoning following use of a water pipe/hookah. Dtsch Arztebl Int 2014; 111:674-9.

8. Hocagil H, Tanrikulu CS, Ülker V, Kaya U, Koca L, Hocagil AC. Asymptomatic Myocardial Injury in a Low Level of Carbon Monoxide Poisoning. J Emerg Med Case Rep2015; 14: 91. [CrossRef]

9. Akkose S, Turkmen N, Bulut M, Akgoz S, Iscimen R, Eren B. An analysis of carbon monoxide poisoning cases in Bursa, Turkey. Eastern Mediterranean health journal $=$ La revue de sante de la Mediterranee orientale = al-Majallah al-sihhiyah li-sharq al-mutawassit 2010; 16: 101-6.

10. Omaye ST. Metabolic modulation of carbon monoxide toxicity. Toxicology 2002; 180: 139-50. [CrossRef] 